\title{
STATISTICAL MODELING TO FORECAST THE STRENGTH OF CONCRETE USING ACCELERATED CURING
}

\author{
Shubham Amritkar ${ }^{1}$, Nishant More ${ }^{2}$ \\ ${ }^{1}$ Civil Engineer, Sandip Institute of Engineering and Management, Maharashtra, India \\ ${ }^{2}$ Civil Engineer, Rizvi College of Engineering, Maharashtra, India
}

\begin{abstract}
It is very much necessary to know the performance of the concrete mix before their actual use on site. The fact that all the required readings of concrete are only obtained after 28 days of curing which becomes a constraint when various grades of concrete are to be used in the same work. Accelerated curing of concrete is a good solution in such cases. IS 9013-1978 gives detailed description as well as guidelines to be adopted during the process of accelerated curing along with an equation to predict the 28 days strength of the concrete. An equation which predicts the achievable strength of concrete under normal curing by using the accelerated curing strength as the dependent parameter is available in the IS code. In this paper we have analyzed the reliability of the equation when additives such as fly ash are used in the mix. At the end it was found that the predicted values largely varied from the actual values obtained from the IS code. In this paper an effort is made to form a new equation by using 3 independent variables such as the fly ash content, water-cement ratio and the accelerated curing strength to obtain fairly reliable results.
\end{abstract}

Key Words: Statistical modelling, Regression, Strength of concrete, Accelerated curing, fly ash

\section{INTRODUCTION}

It is established that a statistically significant correlation exists between 28 day strength and accelerated curing strength of concrete (IS 9013-1978). Tests conducted on various grades of concrete show that the correlation is not affected by the use of different type of aggregates or different brands of cement (IS 9013-1978). Various reliability studies have been conducted on the existing correlation. In their respective studies [6] N. L. Shelke et.al (2013) and [7] V. Jayadevan et.al (2014) has pointed out the variance in actual results from that of the predicted results suggesting that further developments are needed in the subject. The work in this paper has been conducted on the pretext that further developments are needed in the concerned subject. Various studies have pointed out the fact that fly ash which is otherwise a waste material generated from thermal power plants can be used along with cement while preparing concrete. The cementations properties of fly ash and also the reduction it brings about in the amount and cost of cement has very much lead to increased usage of fly ash in the recent years. Prevailing to the present industry conditions about $30 \%$ to $35 \%$ replacement of cement by fly ash has been allowed.(In this study the percentage of fly ash has been kept between $20 \%$ to $30 \%$ ). Because of its increased usage the involvement of fly ash has been studied while analysing the reliability of the equation present in the IS code and it has been observed that the predicted values and actual values varied to a large extent. It thus becomes necessary to redevelop the equation. The viable and the most appropriate solution in this case are clearly the introduction of additional independents such as fly ash content and water cement ratio along with accelerated curing compressive strength of concrete. Two methods of accelerated curing namely warm water method and boiling water method are mentioned in IS 9013-1978. The work in this paper has been done using boiling water method of accelerated curing owing to quicker results and reduced boiling time as compared to that of warm water method.

\subsection{Accelerated Curing}

Accelerated curing is any method by which high early age strength is achieved in concrete. These techniques are especially useful in the prefabrication industry, wherein high early age strength enables the removal of the formwork within 24 hours, thereby reducing the cycle time, resulting in cost-saving benefits. The most commonly adopted curing techniques are steam curing at atmospheric pressure, warm water curing, boiling water curing and autoclaving.

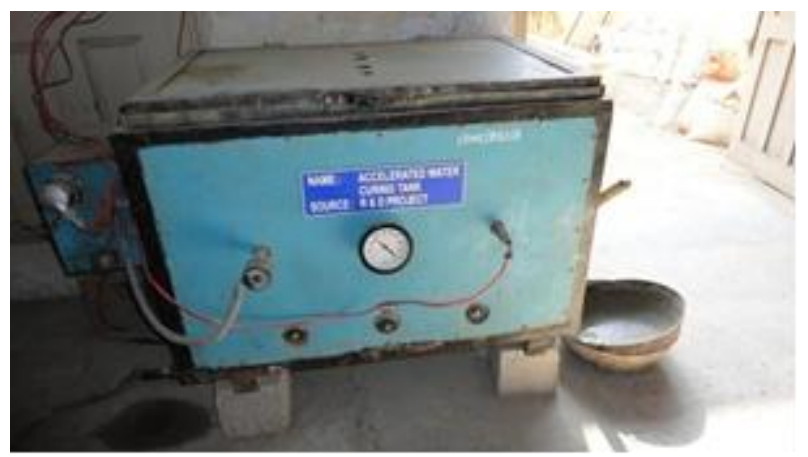

Figure 1: Accelerated Curing Tank

A typical curing cycle involves a preheating stage, known as the "delay period" ranging from 2 to 5 hours; heating at the rate of $22{ }^{\circ} \mathrm{C} /$ hour or $44{ }^{\circ} \mathrm{C} /$ hour until a maximum temperature of $50-82{ }^{\circ} \mathrm{C}$ has been achieved; then 
maintaining at the maximum temperature, and finally the cooling period. The whole cycle should preferably not exceed 18 hours.

It is used to get early high compressive strength in concrete. This method is also used to find out 28 days compressive strength of concrete in 24 hours. (As per IS 9013-1978Method of making, curing and determining compressive strength of accelerated cured concrete test specimens).

The following two methods of accelerated curing are generally used-

A) Warm-water method

B) Boiling-water method.

\subsubsection{Accelerated Curing by Warm Water Method}

1) After the specimens are made, they shall be left to stand undisturbed in their moulds in a place free from vibration at a temperature of $27(+/-) 2{ }^{\circ} \mathrm{C}$ for at least one hour, prior to immersion in the curing tank. The time between the addition of water to the ingredients and immersion of the test specimens in the during tank shall be at least 14 hours but shall not exceed 34 hours.

2) The specimens in their moulds shall be gently lowered into the curing tank and shall remain totally immersed at 55 (+/-) $2^{\circ} \mathrm{C}$ for a period of not less than 19 hours 50 minutes. The specimens shall then be removed from the water, marked for identification, removed from the moulder and immersed in the cooling tank at $27(+/-) 2^{\circ} \mathrm{C}$ before the completion of 20 hours 10 minutes from the start of immersion in the curing tank. They shall remain in the cooling tank for a period of not less than one hour.

\subsubsection{Accelerated Curing by Boiling Water Method}

1) After the specimens have been made, they shall be stored in a place free from vibration, in moist air of at least 90 percent relative humidity and at a temperature of $27(+/-)$ 2 ' $\mathrm{C}$ for 23 hours (+/-) 15 minute from the time of addition of water to the ingredients.

2) The specimens shall then be gently lowered into the curing tank and shall remain totally immersed for a period of 3.5 hours (+/-) 5 minutes. The temperature of the water in the curing tank shall be at boiling $\left(100^{\circ} \mathrm{C}\right)$ at sea level. The temperature of water shall not drop more than $3^{\circ} \mathrm{C}$ after the specimens are placed and shall return to boiling within 15 minutes.

NOTE - In confined places the temperature of the water may be kept just below the boiling point to avoid excessive evaporation.

3) After curing for 3.5 hours (+/-) 5 minutes in-the curing tank, the specimen shall be. Removed from the boiling water, removed from moulds and cooled by immersing in cooling tank at $27(+/-) 2^{\circ} \mathrm{C}$ for 2 hours.

\section{MATERIALS AND METHODS}

In-order to obtain a reliable model as suggested earlier the experimental procedures must be done using a variety in grades of concrete. Keeping this in mind the grades of concrete selected in this project are M30, M40, M50 and M60. Also considering the fact that fly ash is nowadays used as cementing material in combination with cement the designs were prepared using fly ash along with cement, sand and aggregates. All the designs were prepared adhering to the guidelines mentioned in IS-456:2000 and IS10262:2009.

For each grade of concrete two different designs were prepared by varying the fly ash content. Two trials were done for each design owing to the limitations in batching and mixing capacity. The data finally selected as the input is the average of the different independent variables (Accelerated curing compressive strength, Fly ash content, Water cement ratio) selected from each of these trials. The gradation of aggregates was done sticking to the guidelines mentioned in IS-383:1970 and the testing of aggregates was done adhering to the regulations in IS-2386:1963. The specific gravity of aggregates is considered to be uniform for six month period when taken from the same quarry was observed on the site while performing the test for the specific gravity; since all the experimental procedures were done within six months the specific gravity of the aggregates in this case is considered to be fixed at a specific value.

All the cubes were casted in two trials per design. Six blocks were casted in each trial of which three were placed for normal curing and three were placed under accelerated curing. The testing of cubes under accelerated curing was done strictly following the guidelines mentioned in IS9013:1978. Also normal curing was done by completely immersing the blocks in water free from any kind of impurities or any other chemicals.

A simple linear equation is what was finally required. The basis of formulation of the equation was simple linear regression analysis.In statistics, regression analysis is a statistical process for estimating the relationships among dependent and independent variables.

After all the experimental works had been dealt with, from the data obtained a simple linear equation of the following form has been generated- $\mathrm{Y}=\mathrm{Ax}_{1}+\mathrm{Bx}_{2}+\mathrm{Cx}_{3}+\mathrm{D}$ here;

$\mathrm{Y}$ - Predicted 28 day normal curing compressive strength of concrete.

- $\mathrm{X}_{1}=$ Accelerated curing strength of concrete.

- $\mathrm{X}_{2}=$ Fly ash content.

- $\mathrm{X}_{3}=$ Water cement ratio.

The process of regression was done with the help of software SPSS 20.

The coefficient of determination $\mathrm{R}^{2}$ is an indicator of goodness of fit of the model. It represents the percent of the variance in the dependent variable explained by the independent variables. It is a measure of relationship between the predicted variable and the predictors in a 
model. A model with high value of coefficient of determination is said to fit best to determine the dependent variable. The model for which coefficient of determination is close to 1 is said to fit best.

\section{DISCUSSIONS \& RESULTS}

The Table no 1 depicts the specific gravity of different type of aggregates used in the mix design and also the percentage weight of water absorbed by the aggregates during mixing.

Table-1: Specific gravity of aggregates

\begin{tabular}{|c|c|c|c|}
\hline $\begin{array}{c}\text { Sr. } \\
\text { No }\end{array}$ & $\begin{array}{c}\text { Type of } \\
\text { Aggregates }\end{array}$ & $\begin{array}{c}\text { Specific } \\
\text { Gravity }\end{array}$ & $\begin{array}{c}\text { Water } \\
\text { Absorption (\%) } \\
\text { of Aggregates. }\end{array}$ \\
\hline 1 & $\begin{array}{c}10.0 \mathrm{~mm} \\
\text { aggregates }\end{array}$ & 2.841 & 1.06 \\
\hline 2 & $\begin{array}{c}20.0 \mathrm{~mm} \\
\text { aggregates }\end{array}$ & 2.863 & 1.11 \\
\hline 3 & Crushed sand & 2.659 & 4.11 \\
\hline
\end{tabular}

The current equation present in IS 9013-1978 for predicting the 28 day strength of concrete is as follows:

$\mathrm{Y}=8.09+1.64 \mathrm{X}_{1}$

$\mathrm{Y}=28$ day compressive strength of concrete.

$\mathrm{X}_{1}=$ accelerated curing strength of concrete.

The following table represents the mix design along with fly ash content and water cement ratio. Here the designs have been designated as M30-1, M30-2 etc. which depict the change in fly ash content in the design of respective grades.

Table 2: Mix Design

\begin{tabular}{|c|c|c|c|c|c|}
\hline Notation & $\begin{array}{c}\text { watio } \\
\%\end{array}$ & $\begin{array}{c}\text { C } \\
(\mathrm{kg})\end{array}$ & $\begin{array}{c}\text { FA } \\
(\mathrm{kg})\end{array}$ & $\begin{array}{c}\text { CA } \\
(\mathrm{kg})\end{array}$ & $\begin{array}{c}\text { Fly Ash } \\
(\mathrm{kg})\end{array}$ \\
\hline M30-1 & 49.17 & 360 & 693 & 1067 & 80 \\
\hline M30-2 & 44.29 & 350 & 658 & 1178 & 100 \\
\hline M40-1 & 37.65 & 420 & 664 & 1024 & 105 \\
\hline M40-2 & 37.65 & 400 & 664 & 1024 & 125 \\
\hline M50-1 & 33.74 & 450 & 679 & 1042 & 120 \\
\hline M50-2 & 32.75 & 440 & 677 & 1040 & 135 \\
\hline M60-1 & 34.36 & 450 & 711 & 1007 & 100 \\
\hline M60-2 & 32.19 & 460 & 675 & 1007 & 125 \\
\hline
\end{tabular}

Table number 3 shows the compressive strengths obtained from three different methods i.e. the IS code method, 28 day conventional compressive testing method and compressive strength obtained by the method of statistical modeling by accelerated curing.
Table 3: Strengths obtained from various methods

\begin{tabular}{|c|c|c|c|}
\hline Notation & $\begin{array}{c}\text { IS code } \\
\text { Compressive } \\
\text { strength }\end{array}$ & $\begin{array}{c}\text { 28 Day normal } \\
\text { compressive } \\
\text { strength }\end{array}$ & $\begin{array}{c}\text { Predicted } \\
\text { Compressive } \\
\text { Strength }\end{array}$ \\
\hline M30-1 & 44.78 & 36.07 & 35.055 \\
\hline M30-2 & 45.26 & 36.15 & 35.97 \\
\hline M40-1 & 52.67 & 46.96 & 48.14 \\
\hline M40-2 & 55.71 & 44.81 & 47.63 \\
\hline M50-1 & 65.43 & 59.78 & 59.72 \\
\hline M50-2 & 63.12 & 59.70 & 56.79 \\
\hline M60-1 & 78.79 & 70.89 & 71.38 \\
\hline M60-2 & 77.94 & 70 & 69.96 \\
\hline
\end{tabular}

On completion of regression the following equation is obtained:

$\mathrm{Y}=1.225 \mathrm{X}_{1}-48.169 \mathrm{X}_{2}-73.773 \mathrm{X}_{3}+54.627$

$\mathrm{Y}=28$ day compressive strength of concrete.

$\mathrm{X}_{1}=$ accelerated curing strength of concrete.

$\mathrm{X}_{2}=$ fly ash content.

$\mathrm{X}_{3}=$ water content.

The model is a good fit as $\mathrm{R}^{2}$ (Co. efficient of determination) value is .984 which is very close to 1 .

The following graph is the representation of observations. The blue line depicts the actual 28 day strength of concrete obtained after the process of normal curing. The red line depicts the values of strength predicted using the equation in IS-9013:1978. The green line represents the value of strength predicted using the model developed in this study.

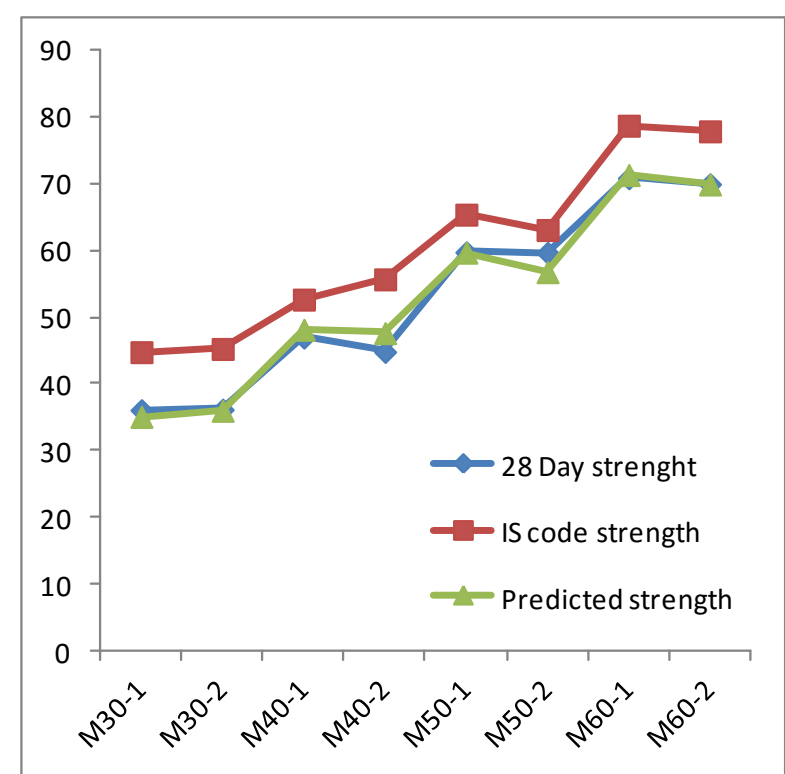

Graph 1: Graphical representation of strengths

It can be clearly seen from the graph that there is a considerable amount of variation in the values predicted using IS code equation from the actual strength. Whereas the closeness between blue and green lines itself explain the closeness between the actual strength and the strength predicted using the model developed in this paper. 


\section{CONCLUSION AND FUTURE SCOPE}

It can be clearly concluded that the values predicted using the developed model is very close to the actual values. An average error percentage of approximately $2.6 \%$ is observed against the average error percentage of $15.45 \%$ when the values are predicted using IS-code equation.

These values are obtained only when using boiling water method for accelerated curing. Due to the inclusion of fly ash in the design the predicted model also depends on fly ash content selected in the mix. A clear conclusion may not be able to be drawn when fly ash is not used in the mix. Further studies and experiments may be hence required to make the equation compatible on a wider scale.

The same model can be developed using different soft wares or tools. As mentioned earlier SPSS 20 software by IBM was used in this project for analysing the data. Preparation of all the data and related calculations were done using Microsoft excel 2010.

\section{Future Scope}

- The same analysis can be done by adopting warm water method for accelerated curing.

- Ground granulated blast furnace slag or (GGBS) is a new admixture which is used along with cement due to its cementing properties. The model can be checked for the scenario where GGBS is used along with cement instead of fly ash. The same analysis as done in this case can be repeated for mixes which include GGBS.

- The behaviour of concrete placed under accelerated curing can also be studied when admixtures are used.

- Incorporation of accelerated curing into mechanized formwork can be studied as this is an upcoming technology in the field of construction. This is likely to facilitate speedy construction.

\section{ACKNOWLEDGEMENT}

The authors would like to extend our gratitude towards Quality Control Engineer, Mr. Stanley Patnaik for mentoring us during the execution of the project.

\section{REFERENCES}

[1] IS-9013:1978, "Method of Making, Curing and Determining Compressive Strength of Accelerated Cured Concrete Test Specimens", Bureau of Indian Standards, New- Delhi.

[2] IS 383- 1970, "Specification of Coarse and Fine Aggregates from Natural Sources for Concrete ", Bureau of Indian Standards, New- Delhi.

[3] IS 2386-1963 (Part 1 - Part 8), "Method of Testing of Aggregates for Concrete", Bureau of Indian Standards, New- Delhi.

[4] IS 456-2000, "Plain and Reinforced Concrete -Code of Practice.” Bureau of Indian Standards, New- Delhi.

[5] IS10262-1982,"Recommended Guidelines for concrete mix design”, Bureau of Indian Standards, New- Delhi.
[6] Shelke N. L," Prediction of Concrete Strength Using Accelerated Curing”, International Journal of Pure and Applied Research in Engineering and Technology, volume1 (8).

[7] V. Jayadevan, V. R Valsalakumary and O. B. Sufeera, "Reliability of accelerated curing techniques for speedy design of concrete mixes -An appraisal of IS 9013:1978 code" Published: The Indian Concrete Journal on February 2014.

[8] Poorav Shah \& Bhavna Shah, "Development of Mathematical Model to Predict Early Age Strength for Blended Cement through Accelerated Curing" Published: National Conference on Recent Trends in Engineering \& Technology on May 2011.

[9] Mr. Shantanu Sureshrao Gholap, "Experimental study of concrete with Blended Cement with Accelerated Curing \& Formation of Mathematical Model" Published: Journal of Mechanical and Civil Engineering (IOSR-JMCE) in April 2014.

[10] N. Yazdani, Filsaime S. Islam, “Accelerated Curing Of Silica-Fume Concrete by" Published: American Society of Civil Engineers on 1st Aug 2008.

[11]M. S. Shetty, "Concrete Technology", S. Chand \& Company Ltd, New Delhi.

[12] Johnson A. Richard," Probability and Statistics for Engineers", Pearson Education (Singapore) Pvt. Ltd.

[13] Murray R. Spiegel and Larry J. Stephens, "Statistics" published by, Tata McGraw Hill, Edition 2000.

[14] Berry G.C., "Statistics for Management" published by, Tata McGraw Hill, New Delhi, Third reprint 2004, pp 417-418.

[15] BhishmaRao G.S.S.;" Probability and Statistics for Engineers", SciTech publications (India) Ltd. Chennai.

[16] Neville A.M, Properties of Concrete", IVth Edition, Pitman Publishing Limited, London 1997.

\section{BIOGRAPHIES}

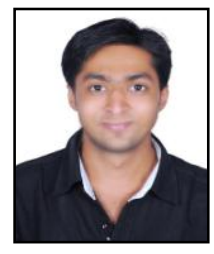

Er. Shubham Amritkar is a Bachelors degree holder in Civil Engineering from University of Pune.

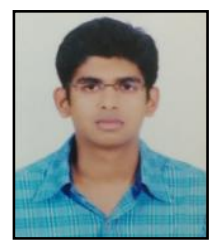

Er. Nishant More is a bachelors degree holder in civil engineering from university of Mumbai. 